This article was downloaded by: [University of Central Florida]

On: 16 September 2008

Access details: Access Details: [subscription number 784375777]

Publisher Taylor \& Francis

Informa Ltd Registered in England and Wales Registered Number: 1072954 Registered office: Mortimer House, 37-41 Mortimer Street, London W1T 3JH, UK

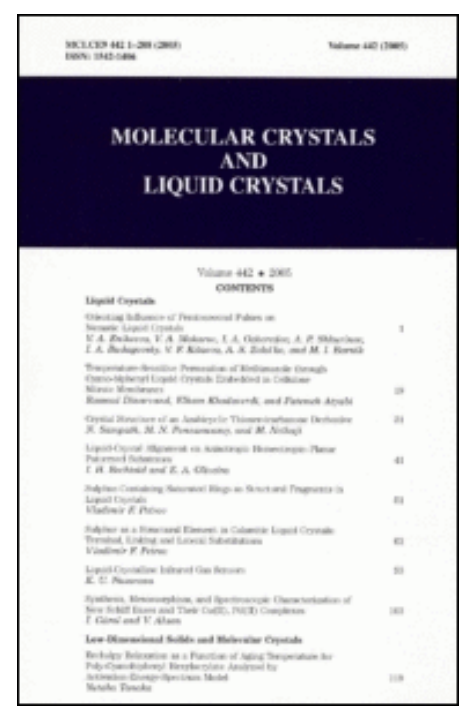

Molecular Crystals and Liquid Crystals

Publication details, including instructions for authors and subscription information:

http://www.informaworld.com/smpp/title content=t713644168

\title{
High Birefringence and Low Crossover Frequency Dual-Frequency Liquid
} Crystals

Qiong Song a; Haiqing Xianyu a; Sebastian Gauza a; Shin-Tson Wu a

a College of Optics and Photonics, University of Central Florida, Orlando, FL, USA

First Published on: 01 January 2008

To cite this Article Song, Qiong, Xianyu, Haiqing, Gauza, Sebastian and Wu, Shin-Tson(2008)'High Birefringence and Low Crossover Frequency Dual-Frequency Liquid Crystals',Molecular Crystals and Liquid Crystals,488:1,179 - 189

To link to this Article: DOI: $10.1080 / 15421400802240573$

URL: http://dx.doi.org/10.1080/15421400802240573

\section{PLEASE SCROLL DOWN FOR ARTICLE}

Full terms and conditions of use: http://www.informaworld.com/terms-and-conditions-of-access.pdf

This article may be used for research, teaching and private study purposes. Any substantial or systematic reproduction, re-distribution, re-selling, loan or sub-licensing, systematic supply or distribution in any form to anyone is expressly forbidden.

The publisher does not give any warranty express or implied or make any representation that the contents will be complete or accurate or up to date. The accuracy of any instructions, formulae and drug doses should be independently verified with primary sources. The publisher shall not be liable for any loss, actions, claims, proceedings, demand or costs or damages whatsoever or howsoever caused arising directly or indirectly in connection with or arising out of the use of this material. 


\title{
High Birefringence and Low Crossover Frequency Dual-Frequency Liquid Crystals
}

\author{
Qiong Song, Haiqing Xianyu, Sebastian Gauza, \\ and Shin-Tson Wu \\ College of Optics and Photonics, University of Central Florida, \\ Orlando, FL, USA
}

\begin{abstract}
The dielectric relaxation and physical properties of some single and double ester compounds were investigated. Experimental results indicate that the double-ester compound has a $3 X$ lower dielectric relaxation frequency and larger dielectric anisotropy than the single ester, but its viscosity is also higher. We have formulated three high birefringence DFLC mixtures and compared their figure-of-merit at elevated temperatures.
\end{abstract}

Keywords: dual frequency; high birefringence; liquid crystal compounds

\section{INTRODUCTION}

A dual frequency liquid crystal (DFLC) exhibits a positive dielectric anisotropy $\left(\Delta \varepsilon=\varepsilon_{\|}-\varepsilon_{\perp}\right)$ at low frequencies, and as the frequency increases $\Delta \varepsilon$ gradually decreases and becomes negative at high frequencies [1-3]. The frequency where dielectric anisotropy changes sign, i.e., $\Delta \varepsilon=0$, is called crossover frequency $\left(f_{c}\right)$. A unique feature of DFLC is that it can be used in a homogeneous cell or a homeotropic cell. For a homogeneous cell, a low frequency voltage is applied to reorient the LC directors and a high frequency voltage to restore the LC back to its initial homogeneous alignment. For a homeotropic cell, the driving frequency has reversed order. Generally speaking, a homogeneous alignment is preferred for phase modulation applications [4] because the positive $\Delta \varepsilon \mathrm{LC}$ materials tend to have higher birefringence and larger dielectric anisotropy because their dipoles are along the 
principal molecular axis. A homeotropic alignment, on the other hand, exhibits an excellent contrast ratio between crossed polarizers and is more favorable for display applications.

In a homogeneous cell, the rise and decay times of the LC directors are described by the following equations [5]:

$$
\begin{gathered}
\tau_{\text {rise }}=\frac{\tau_{o}}{\left(V_{l} / V_{t h, l}\right)^{2}-1}, \\
\tau_{\text {decay }}=\frac{\tau_{o}}{\left(V_{h} / V_{t h, h}\right)^{2}-1},
\end{gathered}
$$

where

$$
\tau_{o}=\gamma_{1} d^{2} / K_{11} \pi^{2}
$$

In Eqs. (1)-(3), $\tau_{\mathrm{o}}$ is the LC directors' free relaxation time [6], $\gamma_{1} / \mathrm{K}_{11}$ is the visco-elastic coefficient, $V_{l}$ and $V_{h}$ are the applied voltages for turning on and turning off the LC cell, $\mathrm{V}_{\text {th, }, ~}$ and $\mathrm{V}_{\text {th,h }}$ are the threshold voltage of the DFLC at low and high frequencies, respectively. In a DFLC cell, both rise and decay times are assisted by a driving voltage. The higher the applied voltage, the faster the response time. Furthermore, the overdrive voltage method [7-9] can be used to accelerate the response speed during rise and decay periods. The fast response DFLC has been used in adaptive optics [10,11] for correcting atmospheric aberrations where a few kilohertz response speed is needed.

From Eqs. (1)-(3), high birefringence, low viscosity, large $\Delta \varepsilon$ at both low and high frequencies, and low crossover frequency are highly desirable. High birefringence enables a thin cell gap to be used which helps to lower the operating voltage and achieve fast response time [12]. Low viscosity is always helpful for shortening response time. A large $|\Delta \varepsilon|$ at both low and high frequency regimes reduces the operating voltage while a low crossover frequency $(<10 \mathrm{kHz})$ would minimize the dielectric heating $[13,14]$ and reduce the cost of driving electronics.

In this paper, we investigated the dielectric relaxation phenomena and electro-optical properties of the positive $\Delta \varepsilon$ single ester and double ester compounds. Results indicate that the double esters have a $\sim 3 \mathrm{X}$ larger dielectric relaxation time constant and higher dielectric anisotropy than the single esters. However, their viscoelastic coefficient is also higher than that of the corresponding single ester compounds. We also studied some lateral four-fluoro phenyl tolane compounds [15] whose dielectric anisotropy is -8 and 
birefringence $\sim 0.35$. These large negative $\Delta \varepsilon$ compounds help to lower the crossover frequency. Using positive cyano-based double esters, strong negative tolane LC compounds, and a biphenyl compound to reduce the melting point of the mixtures, we formulated a high birefringence low crossover eutectic DFLC mixture with $\Delta \mathrm{n} \sim 0.29$, $\Delta \varepsilon \sim 6.8$ at $\mathrm{f}=100 \mathrm{~Hz}$ and -6.2 at $100 \mathrm{kHz}, \gamma_{1} / \mathrm{K}_{11} \sim 32 \mathrm{~ms} / \mu \mathrm{m}^{2}$, and $f_{c} \sim 8.85 \mathrm{kHz}$. In comparison, Merck MLC-2048 DFLC mixture has $\Delta \mathrm{n} \sim 0.21,|\Delta \varepsilon| \sim 3$, and $f_{c} \sim 23 \mathrm{kHz}$.

\section{SINGLE ESTER AND DOUBLE ESTER COMPOUNDS}

We prepared two DFLC mixtures, designated as DFLC-1 and DFLC-2, using a common negative difluoro tolane LC host mixture. In DFLC-1, we mixed $15 \mathrm{wt} \%$ of a single ester positive compound (I) with $85 \mathrm{wt} \%$ of the host LC mixture. Similarly, DFLC-2 was comprised of $15 \mathrm{wt} \%$ double ester positive compound (II) and $85 \mathrm{wt} \%$ host mixture. The molecular structures of compounds (I) and (II) are shown below:
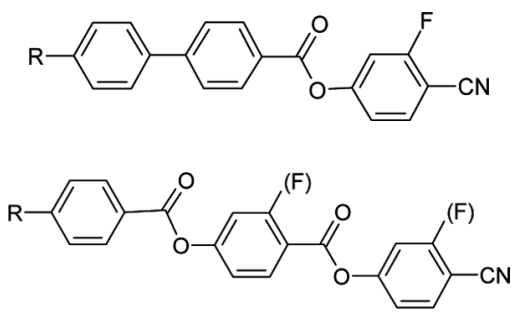

Here, $R$ represents an alkyl chain. The eutectic compositions were calculated from the Schroder-Van Laar equation in order to obtain good miscibility and wide nematic range.

There are two types of polarizations that contribute to the dielectric constant: induced polarization and orientation polarization. The electric field-induced polarization has a very fast response time so that the induced dipole can follow the external field. The orientation polarization, however, exhibits a much longer decay time $\tau$. At a frequency $\omega$ which is much higher than $1 / \tau$, the orientation polarization cannot follow the variations of the external field any longer. Thus the dielectric constant is decreased to $\varepsilon_{\infty}$, which is contributed solely by the induced polarization. In a typical LC compound, e.g., cyano-biphenyl, this relaxation frequency occurs in the megahertz region [16], but mixtures can be made in which this relaxation occurs at a comparatively low frequency, say $\sim \mathrm{kHz}$. 
Debye's theory [17] of dipole relaxation assumes that rotational motion can be described in terms of a single relaxation time as follows:

$$
\begin{gathered}
\varepsilon_{\|}(\omega)=\varepsilon_{\infty}+\frac{\varepsilon_{\|}-\varepsilon_{\infty}}{1+\omega^{2} \tau^{2}} \\
\tau_{\text {molecular }}=\left(2 D_{\perp}\right)^{-1}=I\left(2 k_{B} T \tau_{J}\right)^{-1}
\end{gathered}
$$

In Eq. (5), $D_{\square}$ is the rotational diffusion constant; $\tau_{\mathrm{J}}$ is the relaxation time for the angular momentum about the short axis, $I$ is the moment of inertia, $k_{B}$ is the Boltzmann constant, and $\mathrm{T}$ is the temperature. The low-frequency dispersion $\varepsilon_{\|}(\omega)$ strongly depends on the molecular structural properties such as polarity, rigidity, molecular length and, in the case of mixtures, on the mixture compositions.

In experiment, we measured dielectric anisotropy using a HIOKI 3532-50 LCR meter. Figure 1(a) shows the measured frequency-dependent $\varepsilon_{\|}$of DFLC-1 and DFLC-2, where dots are experimental data and lines are fittings with Eq. (4). The extracted relaxation time is $40 \mu \mathrm{s}$ for DFLC- 1 and $120 \mu$ s for DFLC-2, and their corresponding relaxation frequency is $3979 \mathrm{~Hz}$ and $1326 \mathrm{~Hz}$. This shows the double-ester compound has a $3 \mathrm{X}$ larger dielectric relaxation time constant, i.e. 3X lower relaxation frequency than the single ester compound. The relationship between relaxation frequency and crossover frequency is clearly demonstrated in Figure 1(b) because DFLC-1 and DFLC-2 use the same negative host. The crossover frequency of DFLC-1 and DFLC-2 is $19.5 \mathrm{kHz}$ and $8.65 \mathrm{kHz}$, respectively. Moreover, DFLC-2 has $\sim 2 \mathrm{X}$ larger dielectric anisotropy than DFLC-1 at low frequencies. The detailed dielectric properties of DFLC-1 and DFLC-2 are listed in Table 1.

\section{NEGATIVE PHENYL TOLANE COMPOUNDS}

To lower the crossover frequency further, we need to improve the $\Delta \varepsilon$ of the negative host. Recently, our group has developed some high $\Delta \mathrm{n}$ and large negative $\Delta \varepsilon$ phenyl tolane compounds [15] with their structures shown below:
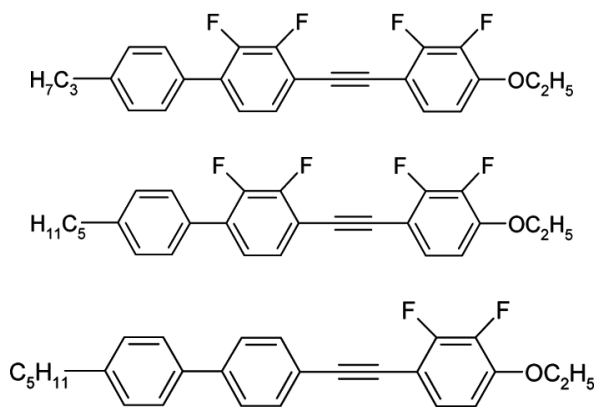


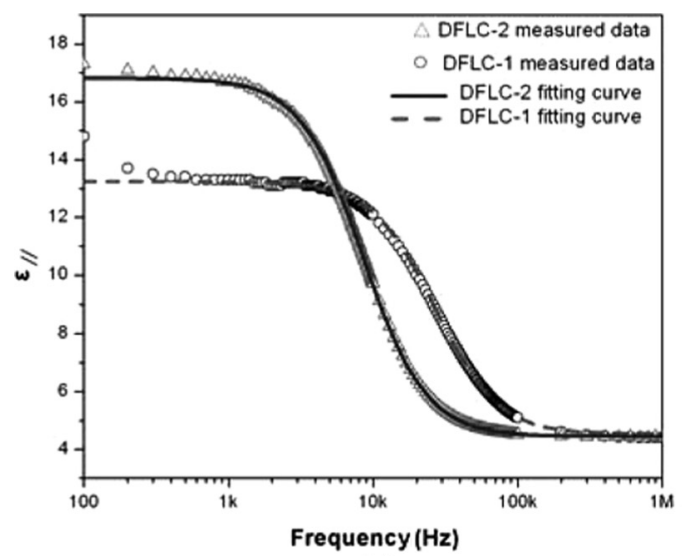

(a)

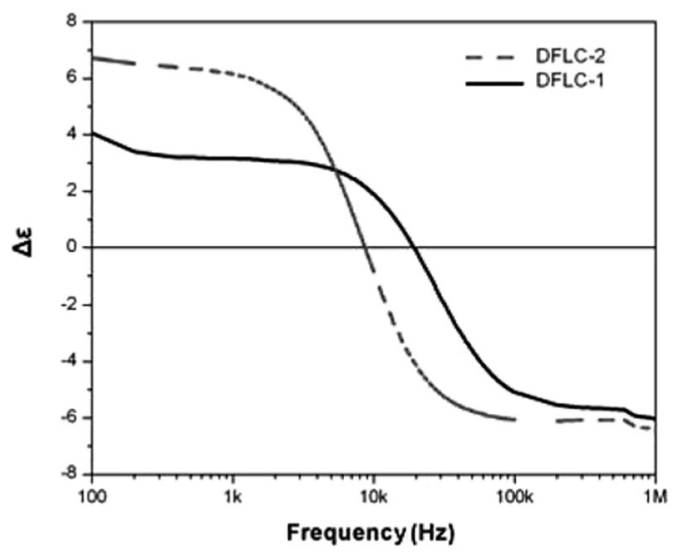

(b)

FIGURE 1 (a) Measured frequency dependent parallel dielectric constant $\left(\varepsilon_{\|}\right)$, and (b) frequency dependent dielectric anisotropy $(\Delta \varepsilon)$ of DFLC-1 and DFLC-2.

TABLE 1 The Measured and Extracted Dielectric Properties of DFLC-1 and DFLC-2

\begin{tabular}{cccccccc}
\hline & $\varepsilon_{\infty}$ & $\varepsilon_{\|}$ & $\tau(\mu s)$ & $f_{r}=1 /(2 \pi \tau)(\mathrm{Hz})$ & $+\Delta \varepsilon$ & $-\Delta \varepsilon$ & $f_{c}(\mathrm{kHz})$ \\
\hline DFLC-1 & 4.5 & 13.2 & 40 & 3979 & 6.8 & -6.2 & 19.5 \\
DFLC-2 & 4.4 & 16.8 & 120 & 1326 & 3.1 & -5.5 & 8.65 \\
\hline
\end{tabular}


TABLE 2 Extrapolated $\Delta \mathrm{n}($ at $\lambda=633 \mathrm{~nm})$ and $\Delta \varepsilon$ (at $f=1 \mathrm{kHz}$ ) of Compounds (III), (IV), and (V). The LC Host is MLC-6608

\begin{tabular}{lcc}
\hline Compounds & $\Delta \mathrm{n}\left(25^{\circ} \mathrm{C}\right)$ & $\Delta \varepsilon\left(23^{\circ} \mathrm{C}\right)$ \\
\hline III & 0.35 & -8.5 \\
IV & 0.32 & -8.5 \\
V & 0.35 & -6.8 \\
\hline
\end{tabular}

Because of their high melting points, we doped each compound in a commercial TFT mixture MLC-6608 to extrapolate its $\Delta \mathrm{n}$ and $\Delta \varepsilon$ values. Results are listed in Table 2.

The birefringence of a liquid crystal is mainly determined by the $\pi$-electron conjugation, differential oscillator strength, molecular shape, and order parameter [18-20]. The rotational viscosity is dependent on the activation energy, molecular moment of inertia (including molecular shape and mass) and temperature [21]. Thus, a linearly conjugated liquid crystal should exhibit a large optical anisotropy while retaining a relatively low rotational viscosity.

The tolane unit which is formed by two phenyl rings linked by a triple bond forms the main part of rigid core of the molecules and defines the principal molecular axis [22]. The unsaturated phenyl ring is rich in $\pi$-electrons. Thus, these rings are particularly desirable for elongating $\pi$-electron conjugation through the rod-like molecule and increasing the polarizability along the principal molecular axis. The triple bond is an effective $\pi$-electron acceptor. In addition, its contribution to viscosity is not so significant. The oxygen atom in the alkoxy chain elongates the $\pi$-electron conjugation but it also increases the viscoelastic coefficient and melting temperature. For the CN group, it has a large dipole moment, but due to the very strong polarization of the carbon-nitrogen triple bond, dimmers are formed by strong intermolecular interactions between the nitrile groups. Thus, its viscosity is relatively high. The main challenge of large negative dielectric anisotropy LCs is that they are difficult to align in a VA cell, but this problem can be solved easily by doping about $15 \%$ of a positive or neutral compound to the negative mixture $[23,24]$.

\section{HIGH PERFORMANCE DFLC MIXTURE}

From the results shown in Sec. II and Sec. III, we formulated a DFLC-3 mixture using the low relaxation frequency double ester positive compounds and large negative $\Delta \varepsilon$ and high $\Delta \mathrm{n}$ phenyl tolane 


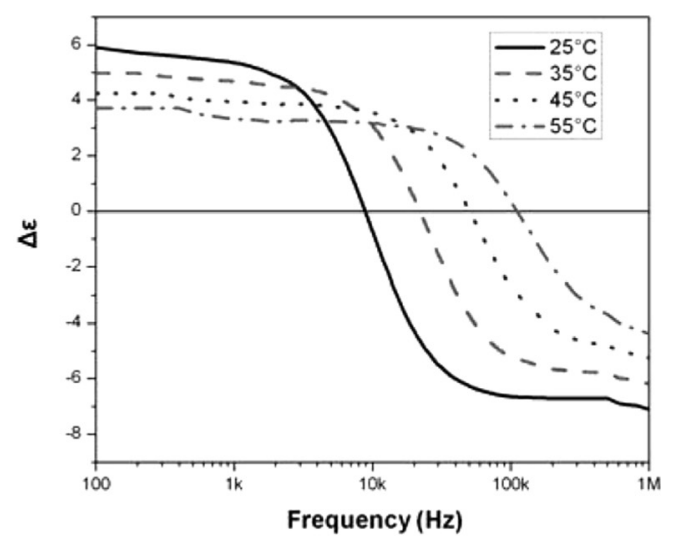

(a)

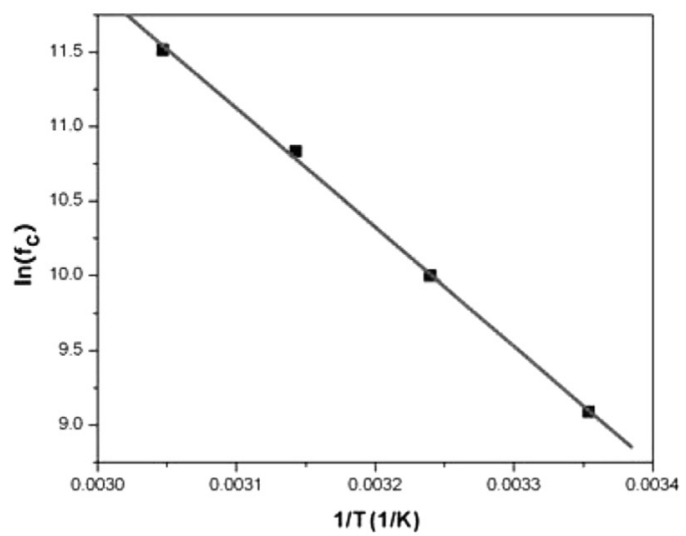

(b)

FIGURE 2 (a) Frequency dependent dielectric anisotropy of DFLC-3. The crossover frequency of DFLC-3 at $25,35,45$ and $55^{\circ} \mathrm{C}$ is $8.85,22.5,50.5$ and $100 \mathrm{kHz}$, respectively. (b) Temperature dependent crossover frequency of DFLC-3. The extrapolated activation energy is $687 \mathrm{meV}$.

compounds (III-V). The comprehensive physical properties of this mixture were measured and evaluated.

The temperature dependent dielectric anisotropy and crossover frequency of DFLC-3 were measured and results shown in Figs. 2(a) and $2(\mathrm{~b})$, respectively. At a given temperature, say $25^{\circ} \mathrm{C}$, the dielectric anisotropy of DFLC-3 is about 6 at $\mathrm{f}=100 \mathrm{~Hz}$ and decreases as the frequency increases and changes sign at $8.85 \mathrm{kHz}$. At $\mathrm{f}=100 \mathrm{kHz}$, $\Delta \varepsilon \sim-6.7$. The observed large negative $\Delta \varepsilon$ results from the strong 
negative compounds (III-V) employed. As the temperature increases, the dielectric anisotropy decreases in proportion to the order parameter $\mathrm{S}$ as following $[25,26]$ :

$$
\Delta \varepsilon \sim S=\left(1-T / T_{c}\right)^{\beta}
$$

where $\mathrm{T}_{\mathrm{c}}$ is the clearing point of the $\mathrm{LC}$ and exponent $\beta$ is a material parameter which is about $0.20 \pm 0.05$ for most liquid crystals.

The crossover frequency is a strong function of the temperature. As the temperature increases, the crossover frequency increases exponentially as [2]:

$$
f_{c} \sim \exp \left(-E / k_{B} T\right)
$$

In Eq. (7), $f_{c}$ is the crossover frequency, E the activation energy, $k_{B}$ the Boltzmann constant, and $\mathrm{T}$ the temperature.

In order to measure the electro-optical properties of DFLC-3, it is necessary to briefly introduce the experimental setup first. In experiment, we prepared homogeneous cells with cell gaps $\mathrm{d} \sim 8 \mu \mathrm{m}$ while a linearly polarized $\mathrm{He}-\mathrm{Ne}$ laser $(\lambda=632.8 \mathrm{~nm})$ was used as the light source. A linear polarizer was placed at $45^{\circ}$ with respect to the LC cell rubbing direction and an analyzer was crossed [27]. The light transmittance was measured by a photodiode detector (New Focus Model 2031) and recorded digitally by a LabVIEW data acquisition system (DAQ, PCI 6110). An ac voltage with $1 \mathrm{kHz}$ square waves was used to drive the LC cell whose inner surfaces were coated with ITO (indium-tin-oxide) electrodes. On top of the ITO, the substrates were overcoated with a thin polyimide alignment film. The buffing induced pretilt angle was about $2-3^{\circ}$. The cell was held in a Linkam LTS 350 Large Area Heating/Freezing Stage equipped with Linkam TMS94 Temperature Programmer. The phase retardation $(\delta)$ of the homogeneous cells was measured by the LabVIEW systems. The LC birefringence $(\Delta \mathrm{n})$ at wavelength $\lambda$ and temperature $\mathrm{T}$ can be obtained by measuring the phase retardation of the homogeneous cell. By measuring the free relaxation (decay) time for a controlled phase change we can calculate the visco-elastic coefficient $\left(\gamma_{1} / K_{11}\right)$ [21].

To compare the performance of DFLC mixtures, a Figure-of-Merit (FoM) which takes phase retardation and visco-elastic coefficient into account is defined as [28]

$$
F_{O} M=\frac{K_{11}(\Delta n)^{2}}{\gamma_{1}} .
$$

The temperature dependence of birefringence, visco-elastic coefficient, and FoM are shown as below: 


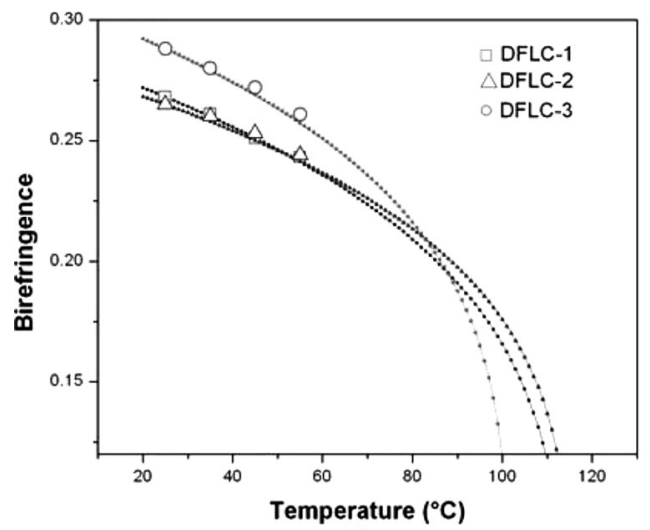

(a)

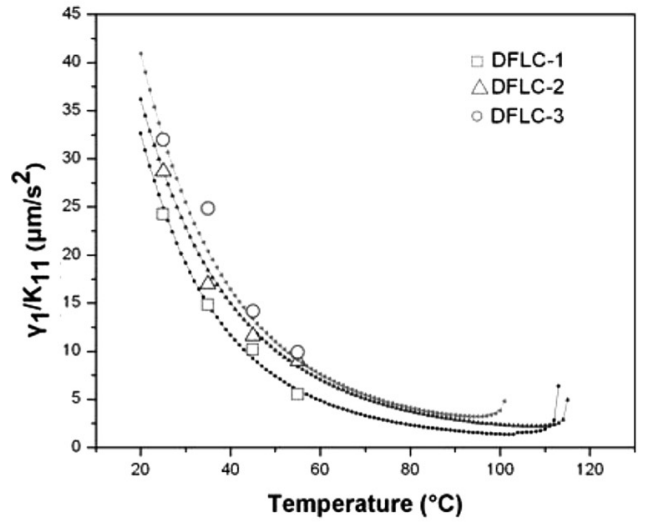

(b)

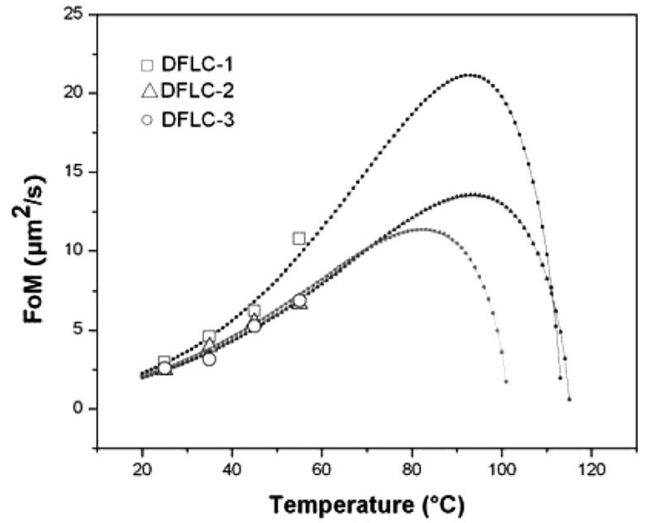

(c)

FIGURE 3 Temperature dependence birefringence, visco-elastic coefficient, and FoM of DFLC-1, -2 and -3. Circles, squares, and triangles are measured data for DFLC-1, DFLC-2 and DFLC-3 respectively. Solid lines are fittings. 
TABLE 3 Measured Physical Properties of DFLC-1, -2, and -3. The Unit of FoM is $\mu \mathrm{m}^{2} / \mathrm{s}$

\begin{tabular}{cccccc}
\hline & $\mathrm{T}_{\mathrm{m}}\left({ }^{\circ} \mathrm{C}\right)$ & $\mathrm{T}_{\mathrm{c}}\left({ }^{\circ} \mathrm{C}\right)$ & $\Delta \mathrm{n}\left(25^{\circ} \mathrm{C}\right)$ & $\gamma_{1} / \mathrm{K}_{11}\left(25^{\circ} \mathrm{C}\right)$ & $\mathrm{FoM}\left(25^{\circ} \mathrm{C}\right)$ \\
\hline DFLC-1 & $<-20$ & 113.4 & 0.27 & 24.2 & 2.95 \\
DFLC-2 & $\sim 4.9$ & 115.1 & 0.27 & 28.7 & 2.44 \\
DFLC-3 & $\sim 2.3$ & 101.5 & 0.29 & 32.0 & 2.58 \\
\hline
\end{tabular}

$$
\begin{gathered}
\Delta n=\Delta n_{o}\left(1-T / T_{c}\right)^{\beta}, \\
\gamma_{1} / K_{11} \sim \exp \left(E / k_{B} T\right) /\left(1-T / T_{c}\right)^{\beta}, \\
K_{11} \Delta n^{2} / \gamma_{1} \sim \Delta n_{o}^{2}\left(1-T / T_{c}\right)^{3 \beta} \exp \left(-E / k_{B} T\right),
\end{gathered}
$$

where $K_{11}$ is the splay elastic constant for a homogeneous cell, $\gamma_{1}$ is the rotational viscosity, $\Delta \mathrm{n}$ is the birefringence, and $\Delta \mathrm{n}_{\mathrm{o}}$ is the birefringence in a completely ordered state $(S=1), E$ is the activation energy of the liquid crystal, and $k_{B}$ is the Boltzmann constant.

We measured the birefringence and visco-elastic coefficient, and then calculated the FoM of these three mixtures. Results are shown in Figures 3(a), 3(b) and 3(c), respectively. At $\mathrm{T}=25^{\circ} \mathrm{C}$, DFLC-3 has the largest birefringence $(\Delta \mathrm{n}=0.29)$, but its visco-elastic coefficient is also the highest. Thus, its FoM is smaller than that of DFLC-1, especially at high temperatures. All the measured results are fitted with Eqs. (9)-(11). As the temperature increases by $10^{\circ} \mathrm{C}$, the rotational viscosity drops by nearly $2 \mathrm{X}$. At a temperature which is far below $T_{c}$, the initial decrease in $\gamma_{1} / \mathrm{K}_{11}$ is much more substantial than that of $\Delta \mathrm{n}$, resulting in an improvement in the FoM as the temperature increases. However, when the temperature keeps on increasing the declination in $\Delta \mathrm{n}$ becomes more drastic. On the other hand, the visco-elastic coefficient gradually saturates resulting in a significant decrease in $\mathrm{FoM}$ as the temperature approaches the clearing point.

Phase transition temperatures were measured using a Differential Scanning Calorimeter (DSC, TA Instrument Model Q-100). The scanning rate was controlled at $1{ }^{\circ} \mathrm{C} / \mathrm{min}$. Table 3 lists the measured physical properties of DFLC- $1,-2$ and -3 at $25^{\circ} \mathrm{C}$.

\section{CONCLUSION}

We have compared the dielectric relaxation frequencies of single and double ester compounds and their effects on the crossover frequency 
of DFLC mixtures. Results indicate that the double-ester compound has a $3 X$ larger dielectric relaxation time constant, i.e. 3X lower relaxation frequency than the single ester compound. Thus, the double ester compounds are favorable for formulating low crossover frequency DFLC mixtures. However, their viscosity is increased dramatically because of the two ester groups. The high $\Delta \mathrm{n}$ and large negative $\Delta \varepsilon$ phenyl-tolane LCs are helpful to boost the birefringence and dielectric anisotropy of the DFLC mixtures, except that their viscosity is relatively large.

\section{REFERENCES}

[1] Bucher, H. K., Klingbiel, R. T., \& VanMeter, J. P. (1974). Appl. Phys. Lett., 25, 186.

[2] Schadt, M. (1982). Mol. Cryst. Liq. Cryst., 89, 77.

[3] Golovin, A. B., Shiyanovskii, S. V., \& Lavrentovich, O. D. (2003). Appl. Phys. Lett., 83, 3864.

[4] Efron, U., Wu, S. T., \& Bates, T. D. (1986). J. Opt. Soc. Am. B, 3, 247.

[5] Khoo, I. C. \& Wu, S. T. (1993). Optics and Nonlinear Optics of Liquid Crystals, World Scientific: Singapore.

[6] Wang, H. Y., Wu, T. X., Zhu, X., \& Wu, S. T. (2004). J. Appl. Phys., 95, 5502.

[7] Wu, S. T. \& Wu, C. S. (1989). J. Appl. Phys., 65, 527.

[8] Wu, S. T. (1990). Appl. Phys. Lett., 57, 986.

[9] Liang, X., Lu, Y. Q., Wu, Y. H., Du, F., Wang, H. Y., \& Wu, S. T. (2005). Jpn. J. Appl. Phys. Part 1, 44, 1292.

[10] Gu, D., Winker, B., Wen, B., Taber, D., Brackley, A., Wirth, A., Albanese, M., \& Landrers, F. (2002). Proc. SPIE, 5553, 68.

[11] Huang, Y. H., Wen, C. H., \& Wu, S. T. (2006). Appl. Phys. Lett., 89, 021103.

[12] Wu, S. T., \& Efron, U. (1986). Appl. Phys. Lett., 48, 624.

[13] Schadt, M. (1981). Mol. Cryst. Liq. Cryst., 66, 319.

[14] Wen, C. H. \& Wu, S. T. (2005). Appl. Phys. Lett., 86, 231104.

[15] Xianyu, H., Gauza, S., Song, Q., \& Wu, S. T. (2007). Liq. Cryst., 34, 1473.

[16] Bose, T. K., Campbell, B., Yagihara, S., \& Thoen, J. (1987). Phys. Rev. A, 36, 5767.

[17] Debye, P. (1929). Polar Molecules, Dover Publications: New York.

[18] Wu, S. T. (1986). Phys. Rev. A, 33, 1270.

[19] Wu, S. T. (1991). J. Appl. Phys., 69, 2080.

[20] Li, J. \& Wu, S. T. (2004). J. Appl. Phys., 95, 896.

[21] Wu, S. T. \& Wu, C. S. (1990). Phys. Rev. A, 42, 2219.

[22] Wu, S. T., Hsu, C. S., \& Chem, J. M. (1997). Mol. Cryst. Liq. Cryst., 304, 441.

[23] Wen, C. H., Gauza, S., \& Wu, S. T. (2005). Appl. Phys. Lett., 87, 191909.

[24] Wen, C. H., Wu, B., Gauza, S., \& Wu, S. T. (2005). J. Display Technology, 1, 234.

[25] de Jeu, W. H. \& Lathouwers, Th. W. (1973). Mol. Cryst. Liq. Cryst., 26, 225.

[26] Haller, I. (1975). Prog. Solid State Chem., 10, 103.

[27] Wu, S. T., Efron, U., \& Hess, L. D. (1984). Appl. Opt., 23, 3911.

[28] Wu, S. T., Lackner, A. M., \& Efron, U. (1987). Appl. Opt., 26, 3441. 